\title{
Understanding Mobile Payment Service Continuous Use Intention: An Expectation - Confirmation Model and Inertia
}

DOI: $10.12776 /$ QIP.V21I3.983

Moungho Park, Jaehyeon Jun, Heejun Park

Received: 19 September 2017 Accepted: 04 October 2017 Published: 30 November 2017

\begin{abstract}
Purpose: With significant interest in mobile payment service(MPS), the amount of research on MPS has increased. However, prior studies have focused on users' first use adoption of MPS. Considering the length of time that has passed since MPSs were first introduced, it has become necessary to investigate usres' continuous use intentions of MPS. Therefore, in this research, we aim to verify which factors are influensive on continuous use intention of MPS.
\end{abstract}

Methodology/Approach: To achieve purpose, we adopt the expectationconfirmation model(ECM) and inertia. Also, we arranged our research in South Korea where has well developed market of MPS. We applied structural equation model to verify the hypothesis and conducted a survey on consumer who had an experiecne with MPS before.

Findings: The findings of this study highlight that importance of perceived usefulness. In this research, percieved usefulness have a significant effect on satisfaction and continuous use intention. Also, our findings emphasize the significant effect of inertia on the continuous use intention of an MPS. These findings have somethig in common with previous researches.

Research Limitation/implication: Because young user constitutes the majority of the respondents, generalizing the finding to individuals of all ages is difficult. Further, we only colledcted sample data form MPS usres in South Korea. Consumer perceptions and therir effects on intention may differ from culture to culture. The robustness of these results may be enhanced by replicating the study across various cultures and multiple consumer age groups. Also, because the previous study which is verifying effect of ECM on MPS is scant, theoretical basis seemed not that much robust. On this study, we struggle to build relationship adapting Inforamtion System (IS) context to MPS environment. On the further study, we expect additional reseraches which are using ECM on various IS environment. 
Originality/Value of paper: This paper is an early research verfiying influencial factors on continuous use intention of MPS. This attempts and research of findings enable to offer timely advice to manager of MPS. Also, we struggle to apply concept of inertia to MPS environment to reflect more actual behavior of consumers.

Category: Research paper

Keywords: mobile payment service; expectation-confirmation model; inertia; continuous use intention; satisfaction

\section{INTRODUCTION}

With the rapid development of mobile technology, mobile services have increasingly become a part of our daily lives (Hwang, Shiau and Jan, 2007). In particular, forecasts of the growth of mobile payment services (MPSs) have been very positive. Attracted by the lucrative market and positive forecasts, service providers have released various MPSs. In particular, many global enterprises have focused on MPSs and implemented their own services (Schierz, Schilke and Wirtz 2010). For example, a leading mobile technology company, Samsung, has been trying to develop its own MPS, called Samsung Pay, and Apple has implemented an MPS called Apple Pay. With the significant increase in interest in MPSs within the marketing field, the amount of research on such services has increased dramatically. Since 1998, many papers related to MPS technology issues have been published, including more than 50 articles on consumers' adoption of MPS (Dahlberg, Guo and Ondrus, 2015). However, these studies have focused only on users' first use of an MPS. Given the length of time that has passed since MPSs were first introduced, as well as the intensely competitive market, with low switching costs for users, it has become necessary to investigate users' continuous use intentions of MPSs. To this end, we adopt the expectationconfirmation model (ECM) proposed by Bhattacherjee to demonstrate the status quo bias effect (Bhattacherjee, 2001b), adapting inertia as suggested by Polites and Karahanna as the theoretical base (Polites and Karahanna, 2012). The model and its variables have been verified in many other contexts of consumer behavior, particularly in the context of information systems (IS).

\section{THEORETICAL BACKGROUND}

\subsection{Previous Researches on Mobile Payment Service}

Research on MPS began soon after the first payment transactions in the mobile device environment in 1997. In the early phase of research, the main stream of research focused on technology issues. Once MPSs were more widely used, researchers started to concentrate on the consumer adoption of such services. As a result, during the past 10 years (2007-2016), a considerable number of articles 
on consumer behavior with regard to MPSs have accumulated. In the initial stages of this period, researchers concentrated on identifying the factors that influenced users' first adoption of an MPS. Here, they wished to understand consumers' preferences and the reasons that consumers chose to use or not use an MPS. To do so, several models were proposed, including the technology acceptance model (Thominathan and Ramayah, 2013), the unified theory of acceptance and use of technology (Liu and Yi, 2017). However, these researches still remain on verifying the first use intentions of users of MPSs. During the past 10 years, the use of MPSs has spread tremendously, forming a significant market. Therefore, it has become necessary to identify and investigate those factors that influence users' continuous use intention of MPSs, a topic on which there is very little research. Thus, this study intends to fill this gap in the current body of research.

\subsection{Expectation-Confirmation Theory}

Introduced by Oliver in 1980, the expectation-confirmation theory (ECT) expresses consumer satisfaction as a function of expectation and expectancy disconfirmation. Using the ECT, Oliver argued that satisfaction affects consumers' attitude change and post-purchase intention (Oliver, 1980). The ECT has since been adapted and extended in consumer behavior and service marketing literature (Anderson and Sullivan, 1993). Then, in 2001, Bhattacherjee suggested an expectation-confirmation model (ECM) for IS continuance (see Fig. 1). Bhattacherjee argued that IS users' continuance decisions are similar to consumers' repurchase decisions because both are influenced by the initial use experience (of the IS or product), and such decisions are closely related to consumer satisfaction (Bhattacherjee, 2001b). Since this study, the ECM has been adapted to verify users' continuance intentions in an IS context. Lee adapted the ECM to verify the continuous use intention of an e-learning service by analyzing a sample of 363 learners for a web-based learning program (Lee, 2010). Kim identified the factors affecting the continuous use intention of a mobile data service (MDS) by analyzing 207 users who had prior experience with an MDS (Kim, 2010).

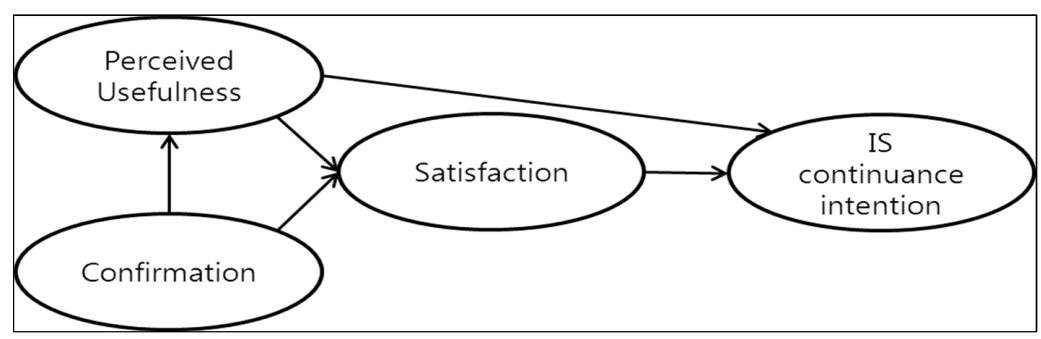

Figure 1 - Expectation-Confirmation Model 


\subsection{Status Quo Bias}

In 1988, Samuelson and Zeckhauser demonstrated empirically why people decide to continue a current course of action rather than switching to a new course of action. They referred to this as the status quo bias (SQB), which they explained by adapting rational decision-making, cognitive misperception, and psychological commitment (Samuelson and Zeckhauser, 1988). SQB explained that people tend to make decisions by considering switching costs and benefits. However, even if the benefits of the new system outweigh the costs of switching, uncertainty about these benefits makes users stay with the incumbent system. 20years after the concept of SQB was established, several studies tried to adapt the SQB to the IS literature. Kim and Kankanhalli (2009) conducted a study on users' resistance to an IS implementation. They adapted the SQB theory to the technology acceptance literature by including variables related to three dimensions of the SQB: rational decision-making, cognitive misperception, and psychological commitment. In addition, Polites and Karahanna utilized the SQB in an IS context to verify how the use of an incumbent IS system negatively affects users' perceptions and usage intentions of a new system (see Fig. 2). They presented the concept of inertia as the persistent use of an incumbent IS system. In a general context, inertia is expressed "remaining at rest or in uniform motion in the same straight line unless acted upon by some external force" (Polites and Karahanna, 2012), and has been used traditionally in consumer behavior literature in the context of brand loyalty. Polites and Karahanna (2012) determined the mediating and moderating impact of inertia in an IS context.

\section{HYPOTEHSIS}

\subsection{Expectation-Confirmation}

As described in section 2.2, Bhattacherjee proposed the ECM in the context of IS continuance. Because the ECM verifies an individual's intention to continue using an IS, many studies have used the model in this context. The ECM has five main hypotheses, based on four variables: continuous use intention; the user's level of satisfaction with the IS; the extent of the user's confirmation of expectations; and perceived usefulness (Lee, 2010). Fig. 1 illustrates the ECM.

\subsubsection{Satisfaction and Continuous Use Intention}

The consumer satisfaction can be defined as a consumer's perception of the degree to which consumers requirements have been fulfilled (Horváth and Michalkova, 2012). With the definition of satisfaction, Keiningham, PerkinsMunn, and Evans verified that consumer satisfaction is influencial on consumer behavior patterns. Furthermore, they varified that high consumer satisfaction results in high consumer loyalty and greater re-purchase intentions (Keiningham, Perkins-Munn and Evans, 2003). In addition, marketing research has shown that 
the major reason for a consumer's decision to re-purchase a product or re-use intention is his/her level of satisfaction (Anderson and Sullivan, 1993; Kotler and Armstrong, 2010; Fernandes and Pedroso, 2016). Bhattacherjee showed empirically that the level of satisfaction with an IS is a critical factor affecting the continuous use intention of a system (Bhattacherjee, 2001b). In line with previous research we therefore hypothesize that:

H1. User satisfaction positively influences a user's continuous use intention of an MPS.

\subsubsection{Perceived Usefulness, Satisfaction and Continuous Use Intention}

Perceived usefulness, in the initial phase, is defined as the extent of an individual's belief that the current system will increase task performance. As the concept of perceived usefulness has been adapted in the IS literature, many researchers have shown the importance of perceived usefulness to users' adoption intentions (Davis, Bagozzi and Warshaw, 1989; Taylor and Todd, 1995; Venkatesh and Davis, 2000). Since Bhattacherjee proposed the ECT, which is combined with the TAM, it has been verified that perceived usefulness affects not only the initial adoption of an IS, but also a user's satisfaction and continuous use intention. Many previous studies have identified the relationship between perceived usefulness, satisfaction, and continuous use intention (Liao, Chen and Yen, 2007; Lin, Wu and Tsai, 2005; Thong, Hong and Tam, 2006; Kang and Lee, 2015). In common with result of earlier studies, we expect positive effect of perceived usefulness on user satisfaction and continuous use intention. Therefore, we hypothesize that:

H2. Perceived usefulness positively influences a user satisfaction of an MPS.

H3. Perceived usefulness positively influences a user's continuous use intention of an MPS.

\subsubsection{Confirmation, Perceived Usefulness and Satisfaction}

The ECM posits that a user's confirmation of expectations will have a positive effect on the perceived usefulness of an IS and on user satisfaction (Bhattacherjee, 2001a). The expectation was initially introduced in 1932 by Tolman, and defined as "consumers' belief which is expecting attribute about product and service" (Tolman, Hall and Bretnall, 1932). Subsequently, Oliver adopted the concept of expectation in the marketing field. He proposed a model that expresses the building phases of consumer satisfaction. Using the model, he argued that satisfaction is built by the level of expectancy confirmation (Oliver, 1980). Referring to these prior studies, Bhattacherjee suggested a hypothesis on the relationship between confirmation and satisfaction. He also proposed a relationship between confirmation and perceived usefulness, supported by the theory of cognitive dissonance (Festinger, 1962), which proposes that users may experience cognitive dissonance or a psychological impact if their pre-acceptance usefulness perceptions are disconfirmed during actual use (Bhattacherjee, 
2001b). In other words, he suggested that confirmation has a positive impact on the perceived usefulness of an IS. After these relations were confirmed, many studies identified a relationship between confirmation, perceived usefulness, and satisfaction of an IS in other product or service fields (Liao, Chen and Yen, 2007). We therefore hypothesize that:

H4. Confirmation positively influences a perceived usefulness of an MPS.

H5. Confirmation positively influences a satisfaction of an MPS.

\subsection{Status Quo Bias}

As we can see in Fig. 2, motives to continue using incumbent system which is affecting inertia divided two kinds of dimension: subconscious and conscious. Based on two different perspectives, our and prior research determined a variable which is representing subconscious motives as a habit and conscious motives as switching costs (Polites and Karahanna, 2012).

\subsubsection{Inertia and Continuous Use Intention}

Individual-level inertia is represented as an attachment to, and persistence of existing behavioral patterns, even if there are better alternatives or incentives to change. Thus, inertia is a rigid continuance of the status quo. In a consumption context, individual inertia refers to a fixed consumption pattern in which consumers are unconsciously attached to the same store of purchase or the same brand of products, based on past consumption experience (Oliver, 1999; Gulati, 1995). The main reason for this phenomenon is familiarity. To avoid the uncertainty associated with using a different store or brand, or the risks of switching costs, consumers prefer to maintain their existing behavior (Lin, Wu and Tsai, 2005; Kuo, Hu and Yang, 2013). To verify this phenomenon, previous researches adapted concept inertia to various contexts (Bawa, 1990; White and Yanamandram, 2004). Another study, which verified the effect of inertia in an IS context, defined inertia as a user's attachment to, and persistence in, using an incumbent system, even if there are better alternatives or incentives to change (Polites and Karahanna, 2012). This study further demonstrated the direct effect of inertia on the intention to use a new system (see Fig. 2). On our study, we also expect effect of inertia on the intention to use MPS. Thus, we hypothesize that:

H6. Inertia negatively influences a continuous use intention of an MPS.

\subsubsection{Traditional Payment Habit and Inertia}

Earlier researcher found that habit strength undermine the amount of information acquired which is regarding product or service and it utilized before a decision is made (Aarts, Verplanken and Knippenberg, 1998). So when a behavior is habitdriven, the person did not think much about it (Mittal, 1988). Habit is often confused with inertia in the literature. One researcher illustrated inertia in brand purchasing as "habituation" (Bawa, 1990), and Fredirck-son and Iaquinto 
equated inertia, momentum, and habit (Fredrickson and Iaquinto, 1989). However, while habit may lead to inertia, the two constructs are clearly distinct. Inertia is a conscious choice to stay with the status quo even in the presence of better alternatives. But habit is referred to action which is automatically triggered by stimulus cues (Polites and Karahanna, 2012). After arranging the relationship between habit and inertia, Polites and Karahanna verified their cause-and-effect relationship. As we can see in Fig. 2, they try to elicit their relationship by using the variable "incumbent system habit" and "inertia". Through this verification, they intend to demonstrate an inhibiting role of habitual us of an incumbent system in technology acceptance (Polites and Karahanna, 2012). In this study, we defined incumbent system of MPS is a traditional payment method such as using credit card, paying in cash. Thus, we posit hypothesis that:

H7. A Traditional payment habit positively influences inertia.

\subsubsection{Switching Cost and Inertia}

Switching cost is defined as "the onetime financial costs and efforts that required customers who associate with the process of switching from one provider to another" (Burnham, Frels and Mahajan, 2003). Also, Samuelson and Zeckhauser argued that "switching cost means that the time and effort required to adapt to a new environment" and "These costs make a switch from the status quo much less likely to occur" (Samuelson and Zeckhauser, 1988). Based on this prior researches Polites and Karahanna (2012) verified the effect of switching costs on inertia. Thus, our study hypothesized that:

H8. Switching costs positively influence inertia.

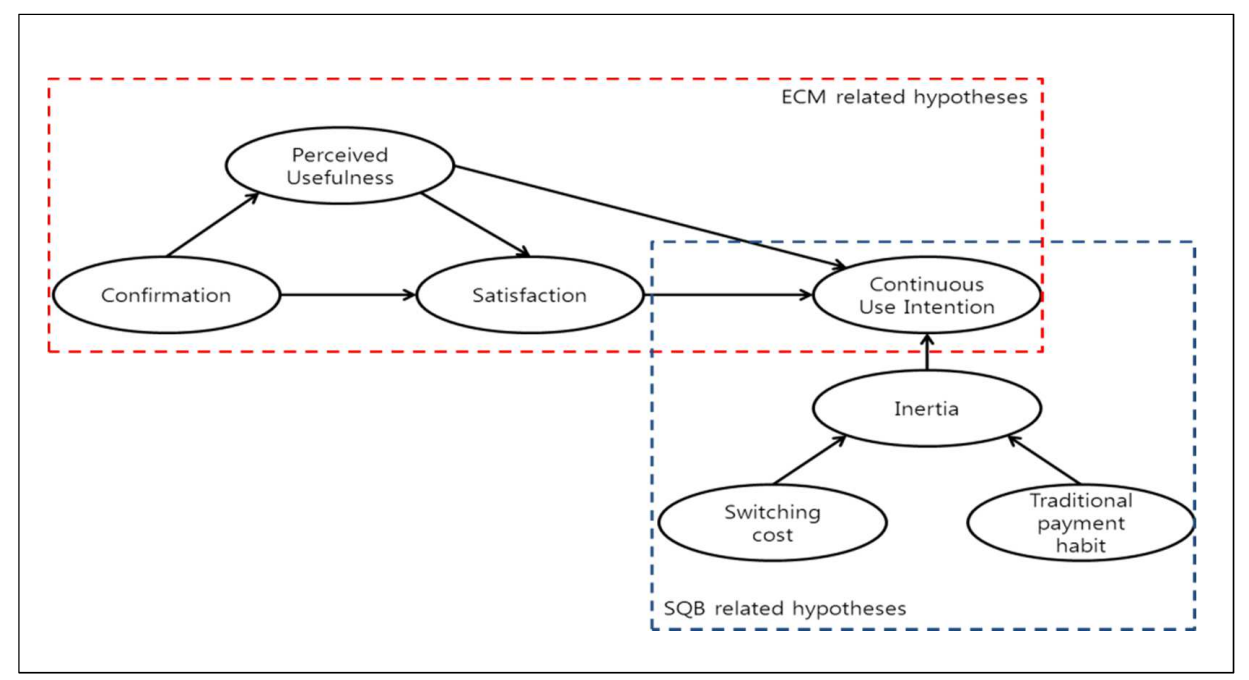

Figure 2 - Research Model 


\section{RESEARCH METHODOLOGY}

\subsection{Reseach Context \& Survey Instrument}

Our research context is set in South Korea, where the MPS market is flourished. South Korea is an appropriate environment in which to identify those factors that influence users' continuous use intentions for an MPS. All theoretical constructs in this study were assessed using multi-item questions. Respondents were asked to indicate the extent to which they agreed/disagreed with these items in relation to their experience of using MPS. Respondents rated each item on a scale of 1 to 5 , where 5 represents "strongly agree" and 1 represents "strongly disagree." The survey was administered to a sample of 237 individuals who had previous experience of MPS. Because we wanted to gather data on consumers' perceptions of the important characteristics of an MPS, we eliminated the answers of individuals who lacked experience with an MPS. Of the 237 individuals contacted, 200 qualified for the final analysis.

Table 1 - Survey Instrument Items

\begin{tabular}{|c|c|c|c|}
\hline Variables & Item & Content & Reference \\
\hline $\begin{array}{l}\text { Continuous } \\
\text { use } \\
\text { intention }\end{array}$ & $\begin{array}{l}\text { INT1 } \\
\text { INT2 } \\
\text { INT3 } \\
\text { INT4 } \\
\text { INT5 }\end{array}$ & $\begin{array}{l}\text { If I could, I would like to continue my use of } \\
\text { MPS } \\
\text { All things considered, I expect to continue suing } \\
\text { MPS during the next } 4 \text { weeks } \\
\text { All things considered, it is likely that I will } \\
\text { continue to use during the next } 4 \text { weeks } \\
\text { I intend to use MPS on my future } \\
\text { I plan to use MPS on my future }\end{array}$ & $\begin{array}{l}\text { (Bhattacherjee, } \\
\text { 2001b) }\end{array}$ \\
\hline Satisfaction & $\begin{array}{l}\text { SAT1 } \\
\text { SAT2 } \\
\text { SAT3 }\end{array}$ & $\begin{array}{l}\text { How do you fell about your overall experience } \\
\text { of MPS use: } \\
\text { Very dissatisfied/very satisfied } \\
\text { Very displeased/very pleased } \\
\text { Very frustrated/very contented }\end{array}$ & $\begin{array}{l}\text { (Bhattacherjee, } \\
\text { 2001b) }\end{array}$ \\
\hline $\begin{array}{l}\text { Perceived } \\
\text { Usefulness }\end{array}$ & $\begin{array}{l}\text { PU1 } \\
\text { PU2 } \\
\text { PU3 }\end{array}$ & $\begin{array}{l}\text { Performance of MPS is of benefit to me } \\
\text { The advantages of MPS outweigh the } \\
\text { disadvantages } \\
\text { Overall, functions offered by MPS is } \\
\text { advantageous }\end{array}$ & $\begin{array}{l}\text { (Bhattacherjee, } \\
\text { 2001b) }\end{array}$ \\
\hline Confirmation & $\begin{array}{l}\mathrm{CF} 1 \\
\mathrm{CF} 2 \\
\mathrm{CF} 3\end{array}$ & $\begin{array}{l}\text { My experience with using MPS was better than } \\
\text { what I expected } \\
\text { The benefit provided by MPS was better than } \\
\text { what I expected } \\
\text { Overall, most of my expectations from using } \\
\text { MPS were confirmed }\end{array}$ & $\begin{array}{l}\text { (Bhattacherjee, } \\
\text { 2001b) }\end{array}$ \\
\hline Inertia & $\begin{array}{l}\text { INE1 } \\
\text { INE2 }\end{array}$ & $\begin{array}{l}\text { I (will) continue retain my traditional payment } \\
\text { method } \\
\text { Because it would be stressful to change }\end{array}$ & $\begin{array}{l}\text { (Polites and } \\
\text { Karahanna, } \\
\text { 2012) }\end{array}$ \\
\hline
\end{tabular}




\begin{tabular}{|c|c|c|c|}
\hline Variables & Item & Content & Reference \\
\hline & INE3 & $\begin{array}{l}\text { Because it is part of my normal routine } \\
\text { Even though I know it is not the best way of } \\
\text { doing things }\end{array}$ & \\
\hline $\begin{array}{l}\text { Switching cost } \\
\text { cost }\end{array}$ & $\begin{array}{l}\mathrm{SC} 1 \\
\mathrm{SC} 2 \\
\mathrm{SC} 3\end{array}$ & $\begin{array}{l}\text { Learning how to use MPS would take much } \\
\text { time } \\
\text { Becoming skillful at using MPS would not be } \\
\text { easy for me } \\
\text { I have already invested a lot of time in learning } \\
\text { to use MPS }\end{array}$ & $\begin{array}{l}\text { (Polites and } \\
\text { Karahanna, } \\
\text { 2012) }\end{array}$ \\
\hline $\begin{array}{l}\text { Traditional } \\
\text { payment } \\
\text { habit }\end{array}$ & $\begin{array}{l}\text { HB1 } \\
\text { HB2 } \\
\text { HB3 } \\
\text { HB4 }\end{array}$ & $\begin{array}{l}\text { Whenever I need to pay, I unconsciously use } \\
\text { traditional method } \\
\text { It would be difficult to control my tendency to } \\
\text { use traditional wallet when I pay } \\
\text { I do not need to devote a lot of mental effort to } \\
\text { deciding that I will use traditional payment } \\
\text { method } \\
\text { Whenever I need to pay, I choose to use } \\
\text { traditional payment method without even being } \\
\text { aware of the choice }\end{array}$ & $\begin{array}{l}\text { (Polites and } \\
\text { Karahanna, } \\
\text { 2012) }\end{array}$ \\
\hline
\end{tabular}

\subsection{Sample}

In June 2016, we conducted a web-based survey and a paper-based survey in South Korea. The characteristics of the respondents are shown in Tab. 2. We had a diverse sample of respondents, with approximately $86 \%$ between the ages of 20 and 29 , and approximately $22 \%$ between the ages of 30 and 39 . All of the survey respondents had experience of using an MPS in the previous six months.

We verified the level of non-response bias by comparing early and late respondents, in other words, those who replied during the first week and the last week. Based on the method proposed by a prior study (Armstrong and Overton, 1977), the t-tests for each case showed that the early and late respondents had no significant differences in terms of their gender, age, or occupation.

Table 2 - Demographic Characteristics of Sample

\begin{tabular}{|l|l|c|c|}
\hline \multicolumn{2}{|l|}{ Classification } & $\begin{array}{l}\text { Frequency } \\
\text { (N= 200) }\end{array}$ & Percentage (\%) \\
\hline Gender & Male & 121 & 60.5 \\
& Female & 79 & 39.5 \\
\hline Age & $20 \mathrm{~s}$ & 172 & 86 \\
& $30 \mathrm{~s}$ & 22 & 11 \\
& $40 \mathrm{~s}$ & 6 & 3 \\
\hline Occupation & Student & 98 & 49 \\
& Office worker & 84 & 42 \\
& Other & 18 & 9 \\
\hline
\end{tabular}




\begin{tabular}{|l|l|c|c|}
\hline \multicolumn{2}{|l|}{ Classification } & $\begin{array}{l}\text { Frequency } \\
\text { (N= 200) }\end{array}$ & Percentage (\%) \\
\hline Experience in past six & Less than 5 times & 20 & 10 \\
months & $5-10$ times & 71 & 30.5 \\
& $10-20$ times & 46 & 36.5 \\
& More than 20 times & 88 & 23 \\
\hline Main usage & Payment & 53 & 44 \\
& Discount coupon & 46 & 26.5 \\
& Loyalty point & 13 & 23 \\
& Other & & 6.5 \\
\hline
\end{tabular}

\section{DATA ANALYSIS AND RESULTS}

A data analysis was conducted using the structural equation modelling technique of partial least squares (PLS), with SmartPLS 2.0. The PLS technique is primarily intended for causal-predictive analyses in highly complex situations (Cho and Jang, 2017). Additionally, the PLS technique is not as restrictive as multivariate normal data distributions are, and the scales may be ordinal. We first checked the validity of the measurement instrument and then tested the hypotheses (Jöreskog and Sörbom, 1989).

\subsection{Measurement Model}

To demonstrate the instruments conceptually, five innovation management researchers and three MPS experts examined the measurement items and reviewed their face validity. We further examined the constructs for convergent and discriminant validity. Convergent validity can be assessed using the following criteria: (1) the factor loadings of the survey items should be significant and exceed 0.7 ; (2) the composite reliability (CR) and Cronbach's alpha should exceed 0.7; and (3) the average variance extracted (AVE) of the constructs should exceed 0.5 (Fornell and Larcker, 1981; Gefen, Straub and Boudreau, 2000). As shown in Tab. 3, the standardized path loadings of all survey items are significant ( $t$ values $>1.96$ ) and larger than 0.7. Furthermore, the CR and Cronbach's alpha for all constructs exceeded 0.7, and the AVE for each construct was larger than 0.5. Therefore, the measures show good convergent validity.

Table 3 - Convergent validity

\begin{tabular}{|l|l|l|l|l|}
\hline Variables & Factor Loadings & AVE & CR & Cronbach's $\boldsymbol{\alpha}$ \\
\hline INT & $0.867,0.874,0.907,0.869,0.884$ & 0.775 & 0.945 & 0.927 \\
\hline SAT & $0.891,0.909,0.899$ & 0.809 & 0.927 & 0.883 \\
\hline PU & $0.897,0.895,0.861$ & 0.782 & 0.915 & 0.860 \\
\hline CF & $0.882,0.903,0.863$ & 0.779 & 0.914 & 0.859 \\
\hline
\end{tabular}




\begin{tabular}{|l|l|l|l|l|}
\hline Variables & Factor Loadings & AVE & CR & Cronbach's $\boldsymbol{\alpha}$ \\
\hline INE & $0.835,0.937,0.896$ & 0.793 & 0.919 & 0.868 \\
\hline SC & $0.886,0.899,0.809$ & 0.749 & 0.899 & 0.832 \\
\hline HB & $0.870,0.911,0.883,0.920$ & 0.803 & 0.942 & 0.918 \\
\hline
\end{tabular}

Note: INT: Continuous use intention, SAT: Satisfaction, PU: Perceived usefulness, CF: Confirmation, INE: Inertia, SC: Switching cost, HB: Habit

Discriminant validity is estimated using the method suggested by Fornell and Larcker (Fornell and Larcker, 1981), in which the square root of the AVE for each construct should exceed the correlation between it and any other constructs. Table 4 shows the correlation matrix, with the correlations among the constructs and the square root of AVE shown in the diagonal elements. The diagonal values exceed the interconstruct correlations. Hence, the result of the discriminant validity test is acceptable.

Table 4 - Discriminant Validity

\begin{tabular}{|c|c|c|c|c|c|c|c|}
\hline & INT & SAT & PU & CF & INE & TC & HB \\
\hline INT & 0.880 & & & & & & \\
\hline SAT & 0.262 & 0.899 & & & & & \\
\hline PU & 0.706 & 0.348 & 0.884 & & & & \\
\hline CF & 0.635 & 0.289 & 0.733 & 0.883 & & & \\
\hline INE & -0.227 & -0.316 & -0.108 & -0.038 & 0.890 & & \\
\hline SC & -0.443 & -0.003 & -0.444 & -0.406 & 0.337 & 0.866 & \\
\hline HB & 0.078 & -0.294 & 0.085 & 0.101 & 0.571 & 0.571 & 0.896 \\
\hline
\end{tabular}

Note: INT: Continuous use intention, SAT: Satisfaction, PU: Perceived usefulness, CF: Confirmation, INE: Inertia, SC: Switching cost, HB: Habit

After testing the measures of the model, we checked for possible common method variance (CMV). Harman's single-factor test examines whether a single factor accounts for a majority of the variance in the data (Podsakoff, et al., 2003). A principal component analysis with eigenvalues larger than one is used to extract the factors. The analysis results showed that CMV is not a serious problem in this study.

\subsection{Structural model}

We tested the hypotheses using the PLS technique. Figure 4 shows the results of the PLS structural model assessment, including the overall explanatory power and estimated path coefficients. The tests of the significance of all paths were performed using the bootstrap resampling procedure. 
Perceived usefulness $(\beta=0.700)$ has a significant influence on the continuous use intention at $\mathrm{p}<0.01$. Thus, $\mathrm{H} 2$ is supported. In addition, perceived usefulness $(\beta=0.295)$ affects satisfaction $(\mathrm{p}<0.05)$. Thus, H3 is supported. Confirmation $(\beta=0.733)$ has a significant influence on perceived usefulness $(\mathrm{p}<0.01)$. Thus, H4 is supported. However, the path coefficients of satisfaction were statistically insignificant for continuous use intention, and the path coefficients of confirmation were statistically insignificant for satisfaction. Thus, H1 and H5 are not supported. Inertia $(\beta=-0.163)$ has a significant influence on the continuous use intention and Switching cost $(\beta=0.318)$ and the traditional payment habit $(\beta$ $=0.560$ ) has a significant influence on inertia. Thus, H6, H7, and $\mathrm{H} 8$ are supported. The explanatory power $\left(\mathrm{R}^{2}\right)$ of perceived usefulness (0.537), satisfaction (0.124), continuous use intention (0.523), and inertia (0.427) are larger than the required threshold of 0.10 (Falk and Miller, 1992).

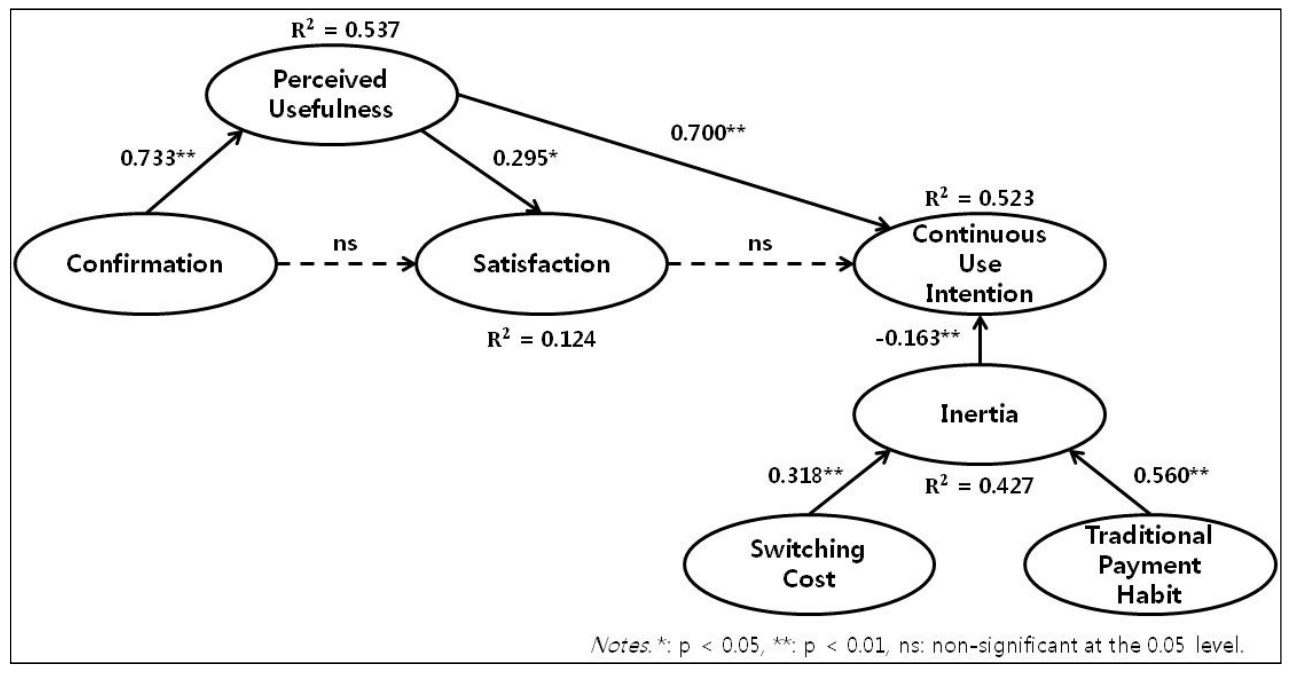

Figure 3 - Results of the Hypothesis Tests

\section{CONCLUSIONS, LIMITATIONS, AND FUTHER RESEARCH}

This study was conducted in South Korea, a country with many MPS users, in order to identify the variables that influence users' continuous use intentions.

First, we focused on the importance of perceived usefulness. As discussed in section 2.2, many studies have been conducted in the context of the continued use of IS, verifying the effect of perceived usefulness and satisfaction on continuous use intentions. Most of these studies reveal that both perceived usefulness and satisfaction are influential. However, in our study, the effect of satisfaction was found not to be significant because the mediating effect of perceived usefulness is too large. We interpret this result as follows.

Considering the characteristics of an MPS, it is possible for several payment services to co-exist in one smart devices (ex, smart phone, tablet PC). More 
specifically, because MPS functions vary, or even if they offer the same functions, their usability differs. Therefore, users are indifferent overall in terms of the total satisfaction provided by a single MPS, but they are interested in the individual functions of MPSs and their perceived usefulness, which is expressed as the extent of an individual's belief that the current system will increase task performance. From an academic perspective, this study adapted and extended the traditional variables of IS continuous use intention to an MPS context. However, our findings differ from those of previous studies. Our results emphasize the importance of perceived usefulness in our context, which requires further research in similar environments, such as money-related mobile applications. In addition, our results can be helpful for MPS companies and their managers. As discussed above, MPS users are strongly affected by perceived usefulness. Therefore, managers and companies have to intensify the ability and performance of an MPS rather than concentrate on overall satisfaction. Furthermore, in order to increase their usage rate in the MPS market, their systems should offer functions offered by other MPSs. This means that concentrating on one particular function is essential. However, at the same time, they should offer other functions that are the same or better as those of other MPSs.

Second, our findings emphasize the significant effect of inertia on the continuous use intention of an MPS. Even if users feel their expectations are confirmed and that the system is useful, inertia will still have a negative influence on their continuous use intention. Furthermore, switching costs and traditional payment habits have a significant effect on inertia. This appears to be similar to the findings of previous studies that examine the role of inertia on consumer behavior in IS (Polites and Karahanna, 2012). These studies demonstrate the effect of a traditional payment habit and familiarity on the continuous use of an IS, and argue that prior system use and habitual behaviors have a negative effect on their continuance intention (Wilson and Lankton, 2013; Limayem and Cheung, 2008). Considering these previous results and our findings, if organizations wish to reduce inertia, they should consider habit disruption and reformation. In order to do so, it is necessary that people have experience using an MPS, which will help to detach them from the familiarity of using traditional payment methods. Thus, simply explaining the advantages and strengths of an MPS is not effective. Instead, the MPS manager should consider events or exhibitions that let people use an MPS directly. In addition, it is important that these events are held regularly and that they introduce new functions and improvements to the MPS. Increasing the inertia of using the MPS will lead to sustainable continuance.

Despite the significant practical and theoretical implications, our study has limitation because the previous study which is verifying effect of ECM on mobile payment service is scant, theoretical basis seemed not that much robust. On this study, we struggle to build relationship adapting IS context to MPS environment. On the further study, we expect additional researches which are using ECM on various other IS environments. 


\section{REFERENCES}

Aarts, H., Verplanken, B. and Knippenberg, A., 1998. Predicting behavior from actions in the past: Repeated decision making or a matter of habit?. Journal of Applied Social Psychology, 28(15), pp.1355-1374.

Anderson, E.W. and Sullivan, M.W., 1993. The antecedents and consequences of customer satisfaction for firms. Marketing science, 12(2), pp.125-143.

Armstrong, J.S. and Overton, T.S., 1977. Estimating nonresponse bias in mail surveys. Journal of marketing research, 14(3), pp.396-402.

Bawa, K., 1990. Modeling inertia and variety seeking tendencies in brand choice behavior. Marketing Science, 9(3), pp.263-278.

Bhattacherjee, A., 2001a. An empirical analysis of the antecedents of electronic commerce service continuance. Decision support systems, 32(2), pp.201-214.

Bhattacherjee, A., 2001b. Understanding information systems continuance: an expectation-confirmation model. MIS quarterly, 25(3), pp.351-370.

Burnham, T.A., Frels, J.K. and Mahajan, V., 2003. Consumer switching costs: a typology, antecedents, and consequences. Journal of the Academy of marketing Science, 31(2), pp.109-126.

Cho, I. and Jang, Y.S., 2017. Cultural Difference of Customer Equity Drivers on Customer Loyalty: A Cross-National Comparison between South Korea and United States. Quality Innovation Prosperity, 21(2), pp.01-19.

Dahlberg, T., Guo, J. and Ondrus, J., 2015. A critical review of mobile payment research. Electronic Commerce Research and Applications, 14(5), pp.265-284.

Davis, F.D., Bagozzi, R.P. and Warshaw, P.R., 1989. User acceptance of computer technology: a comparison of two theoretical models. Management science, 35(8), pp.982-1003.

Falk, R.F. and Miller, N.B., 1992. A primer for soft modeling. OH, Akron: University of Akron Press.

Fernandes, T. and Pedroso, R., 2016. The effect of self-checkout quality on customer satisfaction and repatronage in a retail context. Service Business, pp.124.

Festinger, L., 1962. A theory of cognitive dissonance. CA, Paloalto: Stanford university press.

Fornell, C. and Larcker, D.F., 1981. Evaluating structural equation models with unobservable variables and measurement error. Journal of marketing research, 18(1), pp.39-50.

Fredrickson, J.W. and Iaquinto, A.L., 1989. Inertia and creeping rationality in strategic decision processes. Academy of management journal, 32(3), pp.516542. 
Gefen, D., Straub, D. and Boudreau, M.-C., 2000. Structural equation modeling and regression: Guidelines for research practice. Communications of the association for information systems, 4(7), pp.1-77.

Gulati, R., 1995. Does familiarity breed trust? The implications of repeated ties for contractual choice in alliances. Academy of management journal, 38(1), pp.85-112.

Horváth, M. and Michalkova, A., 2012. Monitoring Customer Satisfaction in Service Industry: A Cluster Analysis Approach. Quality Innovation Prosperity, 16(1), pp.49-54.

Hwang, R.-J., Shiau, S.-H. and Jan, D.-F., 2007. A new mobile payment scheme for roaming services. Electronic Commerce Research and Applications, 6(2), pp.184-191.

Jøreskog, K.G. and Sørbom, D., 1989. LISREL 7: A guide to the program and applications. IL, Chicago: SPSS.

Kang, Y.J. and Lee, W.J., 2015. Self-customization of online service environments by users and its effect on their continuance intention. Service Business, 9(2), pp.321-342.

Keiningham, T.L., Perkins-Munn, T. and Evans, H., 2003. The impact of customer satisfaction on share-of-wallet in a business-to-business environment. Journal of Service Research, 6(1), pp.37-50.

Kim, B., 2010. An empirical investigation of mobile data service continuance: Incorporating the theory of planned behavior into the expectation-confirmation model. Expert Systems with Applications, 37(10), pp.7033-7039.

Kim, H.-W. and Kankanhalli, A., 2009. Investigating user resistance to information systems implementation: A status quo bias perspective. MIS quarterly, 33(3), pp.567-582.

Kotler, P. and Armstrong, G. 2010. Principles of marketing. UK, London: pearson education.

Kuo, Y.-F., Hu, T.-L. and Yang, S.-C., 2013. Effects of inertia and satisfaction in female online shoppers on repeat-purchase intention: The moderating roles of word-of-mouth and alternative attraction. Managing Service Quality: An International Journal, 23(3), pp.168-187.

Lee, M.-C., 2010. Explaining and predicting users' continuance intention toward e-learning: An extension of the expectation-confirmation model. Computers \& Education, 54(2), pp.506-516.

Liao, C., Chen, J.-L. and Yen, D.C., 2007. Theory of planning behavior (TPB) and customer satisfaction in the continued use of e-service: An integrated model. Computers in human behavior, 23(6), pp.2804-2822. 
Limayem, M. and Cheung, C.M., 2008. Understanding information systems continuance: The case of Internet-based learning technologies. Information \& management, 45(4), pp.227-232.

Lin, C.S., Wu, S. and Tsai, R.J., 2005. Integrating perceived playfulness into expectation-confirmation model for web portal context. Information \& management, 42(5), pp.683-693.

Liu, P. and Yi, S.-P., 2017. The Effects of Extend Compatibility and Use Context on NFC Mobile Payment Adoption Intention. Advances in Human Factors and System Interactions, 497, pp.57-68.

Mittal, B., 1988. Achieving Higher Seat Belt Usage: The Role of Habit in Bridging the Attitude-Behavior Gap1. Journal of Applied Social Psychology, 18(12), pp.993-1016.

Oliver, R.L., 1980. A cognitive model of the antecedents and consequences of satisfaction decisions. Journal of marketing research, 17(4), pp.460-469.

Oliver, R.L., 1999. Whence consumer loyalty? The Journal of Marketing, 63, pp.33-44.

Podsakoff, P.M., Mackenzie, S.B., Lee, J.-Y. and Podsakoff, N.P., 2003. Common method biases in behavioral research: a critical review of the literature and recommended remedies. Journal of applied psychology, 88(5), pp.879-903.

Polites, G.L. and Karahanna, E., 2012. Shackled to the status quo: The inhibiting effects of incumbent system habit, switching costs, and inertia on new system acceptance. MIS quarterly, 36(1), pp.21-42.

Samuelson, W. and Zeckhauser, R., 1988. Status quo bias in decision making. Journal of risk and uncertainty, 1(1), pp.7-59.

Schierz, P.G., Schilke, O. and Wirtz, B.W., 2010. Understanding consumer acceptance of mobile payment services: An empirical analysis. Electronic commerce research and applications, 9(3), pp.209-216.

Taylor, S. and Todd, P.A., 1995. Understanding information technology usage: A test of competing models. Information systems research, 6(2), pp.144-176.

Thominathan, S. and Ramayah, T. 2013. Towards Understanding the Intention to Use and Continuance Usage Intention of E-Filing System in Malaysia: The Moderating Role of Perceived Risk. Research and Development in E-Business through Service-Oriented Solutions, pp.307-323.

Thong, J.Y., Hong, S.-J. and Tam, K.Y., 2006. The effects of post-adoption beliefs on the expectation-confirmation model for information technology continuance. International Journal of Human-Computer Studies, 64(9), pp.799810. 
Tolman, E.C., Hall, C.S. and Bretnall, E., 1932. A disproof of the law of effect and a substitution of the laws of emphasis, motivation and disruption. Journal of Experimental Psychology, 15(6), pp. 601-614.

Venkatesh, V. and Davis, F.D., 2000. A theoretical extension of the technology acceptance model: Four longitudinal field studies. Management science, 46(2), pp.186-204.

White, L. and Yanamandram, V., 2004. Why customers stay: reasons and consequences of inertia in financial services. Managing Service Quality: An International Journal, 14(2/3), pp.183-194.

Wilson, E.V. and Lankton, N.K., 2013. Effects of prior use, intention, and habit on it continuance across sporadic use and frequent use conditions. Communications of the Association for Information Systems, 33(3), pp.33-46.

\section{ABOUT AUTHORS}

Moungho Park, Ph.D. Candidate, Department of Convergence Technology Management Engineering, Yonsei University, Republic of Korea, e-mail: yami_27@naver.com.

Jaehyeon Jun, Ph.D. Candidate, Department of Industrial Engineering, Yonsei University, Republic of Korea, e-mail: theojay@yonsei.ac.kr.

Heejun Park, Corresponding Author, Professor, Department of Industrial Engineering, Yonsei University, Republic of Korea, e-mail: h.park@yonsei.ac.kr, Telephone: +82 22123 5717, Fax: +82 23647807 .

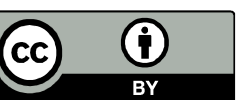

(C) 2017 by the authors. Submitted for possible open access publication under the terms and conditions of the Creative Commons Attribution (CC-BY) license (http://creativecommons.org/licenses/by/4.0/). 